\title{
Characterisation of Klebsiella pneumoniae Xylanase and Increment of Its Activity in Heterologous Expression System
}

\author{
MOHD HASNAIN HUSSAIN*, SUHAILA ZAINOL, NIKSON FATT-MING CHONG \& \\ AWANG AHMAD SALLEHIN AWANG HUSAINI \\ Department of Molecular Biology, Faculty of Resource Science and Technology, Universiti Malaysia \\ Sarawak, 94300 Kota Samarahan, Sarawak, Malaysia
}

\begin{abstract}
A xylanase DNA sequence with a total length of $642 \mathrm{bp}$ was previously isolated from a xylanolytic Klebsiella pneumoniae. Xylanase gene primers were designed with the addition of BamH1 and EcoR1 restriction enzyme sites in order get a full xylanase gene that is in-frame with pSTAG expression vector. The isolated xylanase gene was amplified using the designed primers through PCR, then cloned and expressed in E. coli BL21 (DE3). In-silico characterization showed that the recombinant xylanase has a molecular weight of $23.9 \mathrm{kDa}$ and a pI of 9.32. The signal peptide cleavage site for the recombinant xylanase was predicted to be between residues 61 and 62 . The activity of the crude recombinant xylanase was $2.015 \mathrm{U} / \mathrm{mL}$, which was higher than the crude native xylanase activity, with maximum at $0.642 \mathrm{U} / \mathrm{mL}$. Staining of the birchwood xylan agar plate with Congo red showed a clearing zone around E. coli BL21 (DE3) colonies with recombinant pSTAG plasmid even without being induced with IPTG. This implied leaky expression of the E. coli BL21 (DE3) secretion system, which recognized the signal sequence of the recombinant xylanase, and proceeded to cleave and secreted out the mature protein into the culture medium. MALDI-TOF analysis of a $20 \mathrm{kDa}$ protein present in the culture medium confirmed that the recombinant xylanase had been secreted into the culture medium.
\end{abstract}

Keywords: Heterologous expression, Klebsiella pneumoniae, recombinant xylanase

\section{INTRODUCTION}

Xylan consists of $\beta$-1,4-linked xylopyranosyl residues. It is the second most abundant polysaccharide and an important component that makes up the plant cell wall. Due to the heterogeneity and complexity of the xylan structure, the complete hydrolysis of xylan is carried out by a xylanolytic enzyme system. Endo-1,4- $\beta$-D-xylanase (EC 3.2.1.8) is part of this complex system (Singh et al., 2007). Xylanase cleaves the xylan backbone at 1-4 carbon linkages to produce xylooligosaccharides and xylose (Kulkarni et al., 1999). From a biotechnology perspective, xylanase is an important enzyme because of its thermal stability and its ability to work alone or in combination with other enzymes, making it suitable for a number of industrial applications. Examples of xylanase applications include its use in the kraft process and biobleaching in the paper and pulp industry (Helianti et al., 2008; Kulkarni et al., 1999; Te'o et al., 2000).
Heterologous expression of a gene encoding $\beta-1,4-e n d o x y l a n a s e$ in E. coli BL21 (DE3) was performed in this study. The xylanase gene was isolated from xylanolytic Klebsiella pneumoniae, a bacterium that had been locally isolated from soil from a sago plantation by Hussain et al. (2011). Here, we report on the expression of a xylanase gene from $K$. pneumoniae in E. coli BL21 (DE3) and to determine the characteristics of the recombinant xylanase expressed. To our knowledge, there are no prior publications that describe the isolation and heterologous expression of a xylanase gene from $K$. pneumoniae. Xylanase genes are commonly isolated from genus Bacillus which are abundantly found in soil (Gardener, 2004; Nakamura et al., 1993; Touzel et al., 2000). Thus the isolation of a xylanase gene from $K$. pneumoniae from agricultural soil suggests that xylanase might be naturally occurring among soil-inhabiting microbes. 


\section{MATERIALS AND METHODS}

\section{Bacterial strains and plasmids}

E. coli JM109 strain was used as a host for plasmid amplification and E. coli BL21 (DE3) (Novagen) strain was used as a host for protein expression. Plasmids used in this experiment were pGEM-T Easy Vector (Promega) and pSTAG expression vector (Edwards et al., 1999). The xylanase gene had been cloned into the pGEM-T Easy Vector in previous work by Hussain et al. (2011).

\section{Xylanase gene amplification and subcloning}

The primers were designed based on the isolated xylanase gene from K. pneumoniae by Hussain et al. (2011). The designed primers were 5'-GCG GAT CCA TGT TTA AGT TTA AAA AGA ATT TC-3'as a forward primer and 5'-GCG AAT TCT ATT ACC ACA CTG TTA CGT TAG-3' as a reverse primer. The italic and underlined sequences show the restriction enzyme BamH1 site (forward primer) and EcoR1 site (reverse primer) for subcloning into pSTAG expression vector. PCR amplification using the designed xylanase gene primers and template plasmid DNA was performed using $P f u$ DNA polymerase under the following conditions: $94^{\circ} \mathrm{C}$ for $3 \mathrm{~min}$, then 30 cycles of $94^{\circ} \mathrm{C}$ for $45 \mathrm{~s}, 52^{\circ} \mathrm{C}$ for $1 \mathrm{~min}$, and $72^{\circ} \mathrm{C}$ for $2 \mathrm{~min}$ for each cycle, and a final $72^{\circ} \mathrm{C}$ for $5 \mathrm{~min}$. The PCR product matching the predicted size was purified using GF-1 PCR Clean Up Kit (Vivantis). The xylanase PCR product was digested using BamH1 and EcoR1 restriction enzymes, ligated into linearised pSTAG expression vector with the same restriction enzymes, and transformed into $E$. coli JM109. Positive clones harbouring recombinant pSTAG plasmid were identified through colony PCR.

\section{Bioinformatics analysis of xylanase gene}

Automated sequencing of the recombinant pSTAG plasmid was done by First BASE Laboratories Sdn Bhd (Selangor, Malaysia). Translation of DNA sequence to amino acid sequence was performed using ExPASy Bioinformatics Resource Portal (http://expasy. org/). Pairwise alignment was performed by using ClustalW2 (http://www.ebi.ac.uk/Tools/ $\mathrm{msa} /$ clustalw2/). In-silico characterization for molecular weight and isoelectric point $(\mathrm{pI})$ was predicted using ExPASy Bioinformatics Resource Portal (http://expasy.org/), while signal peptide was predicted using PrediSi Bioinformatics Tool (http://www.predisi.de/).

\section{Transformation into E. coli BL21 (DE3)}

Recombinant pSTAG plasmid and empty pSTAG plasmid were transformed into $E$. coli BL21 (DE3) using the heat shock method. The empty pSTAG plasmid would act as a negative control.

\section{Confirmation of xylanase activity through Congo red agar staining}

M9 minimal agar containing ampicillin (50 $\mu \mathrm{g} / \mathrm{mL}$ ) and $1 \%$ birchwood xylan (Sigma) was used to grow the E. coli BL21 (DE3). A single colony of E. coli BL21 (DE3) harboring the recombinant pSTAG plasmid was picked and streaked onto the agar plate, side by side with the negative control. After incubation at $37^{\circ} \mathrm{C}$ overnight, the colonies were induced with a drop of IPTG to a final concentration of 0.4 $\mathrm{mM}$. Replicate plates were also prepared, but IPTG was not added to the replicate plates. Following overnight incubation, all plates were stained with $1 \%$ Congo red solution and destained by washing with $1 \mathrm{M} \mathrm{NaCl}$.

\section{Expression of xylanase in liquid medium}

The E. coli BL21 (DE3) harboring the recombinant pSTAG plasmid was cultured in LB broth supplemented with ampicillin (50 $\mu \mathrm{g} / \mathrm{mL}$ ) at $30^{\circ} \mathrm{C}$ for 10 hours with shaking at $180 \mathrm{rpm}$ under two conditions; with and without the addition of $1 \%$ glucose. Protein expression was induced with addition of IPTG to a final concentration of $0.4 \mathrm{mM}$. Cells were harvested by centrifugation at $5000 \mathrm{x} \mathrm{g}$ for 5 $\min$ at $4^{\circ} \mathrm{C}$.

\section{Protein extraction}

Freeze and thaw method using liquid nitrogen was carried out to obtain the soluble and insoluble protein fraction (Wanarska et al., 2007). To extract the soluble fraction, the 
frozen cell pellet was resuspended in a soluble protein buffer $(20 \mathrm{mM}$ sodium phosphate, 0.5 $\mathrm{M} \mathrm{NaCl}$ and 20-60 mM imidazole at $\mathrm{pH}$ 7.4) and the sample was frozen and thawed several times. The sample was centrifuged at $4000 \mathrm{x} \mathrm{g}$ for $40 \mathrm{~min}$ at $4^{\circ} \mathrm{C}$, and the supernatant (soluble fraction) was collected. To extract the insoluble fraction, the pellet was resuspended in insoluble protein buffer (6 M urea, $20 \mathrm{mM}$ sodium phosphate, $0.5 \mathrm{M} \mathrm{NaCl}$ and $20 \mathrm{mM}$ imidazole at $\mathrm{pH}$ 7.4), incubated overnight at $4^{\circ} \mathrm{C}$ and centrifuged at $4000 \mathrm{x} \mathrm{g}$ for $40 \mathrm{~min}$ at $4^{\circ} \mathrm{C}$. For the media fraction, culture media was precipitated overnight at $-20^{\circ} \mathrm{C}$ using $0.1 \mathrm{M}$ ammonium acetate in methanol.

\section{SDS-PAGE and Western blot immunodetection}

The total cell protein, soluble fraction, insoluble fraction, and media fraction were checked for xylanase expression using 15\% SDS-PAGE gels stained with Coomassie blue. For Western blot analysis, the proteins were transferred onto a nitrocellulose membrane according to standard procedure (Bio-Rad Laboratories) using the tank transfer method. $\mathrm{S} \cdot$ Tag Western Blot Kit was used according to the $\mathrm{S} \cdot \mathrm{Tag}^{\mathrm{TM}}$ System (Novagen) instruction manual. The transferred membrane was blocked briefly with gelatin, and then incubated with S-protein alkaline phosphatase conjugate. NBT/BCIP substrate was used to visualize target bands.

\section{MALDI-TOF analysis}

Several spots from a Coomassie stained SDSPAGE gel were excised, pooled together, and air dried. MALDI-TOF mass spectrometry and analysis of the MALDI-TOF spectra using Mascot sequence matching software [Matrix Science] with Ludwig NR Database was performed by Proteomics International (Australia).

\section{Crude recombinant enzyme activity}

The activity of the crude recombinant xylanase enzyme using the soluble protein fraction was determined using the Bicinchoninic Acid (BCA) assay, which was carried out based on the protocol described in Hussain et al. (2003). The amount of reducing sugar released was determined based on a glucose standard curve. One unit of xylanase activity was defined as the amount of enzyme that released $1 \mu \mathrm{mol}$ of reducing sugar per min under the assay condition.

\section{RESULTS AND DISCUSSION}

The isolated xylanase gene is from family 11 glycoside hydrolase and showed similarity to Bacillus spp., although 16S rRNA showed that the bacterium closely resembled Klebsiella. Insilico characterization of the isolated xylanase gene showed that it has an open reading frame (ORF) of 642 bp encoding 213 amino acids, and is predicted to code for a xylanase with a molecular weight of $23.3 \mathrm{kDa}$ and an isoelectric point of 9.44, which is quite similar to the xylanase isolated by Jalal et al. (2009) from B. subtilis, as well as Helianti et al. (2008) and Lee et al. (2008) from $B$. licheniformis.

The PCR amplification using the designed primers produced a fragment of about $650 \mathrm{bp}$ (Figure 1), which matched the expected size of $642 \mathrm{bp}$ of the xylanase gene from Bacillus. The PCR product was then subcloned into pSTAG expression vector, and then transformed into $E$. coli JM109. Positive clones harbouring recombinant pSTAG plasmid were chosen through colony PCR. Plasmids were extracted and sent for sequencing.

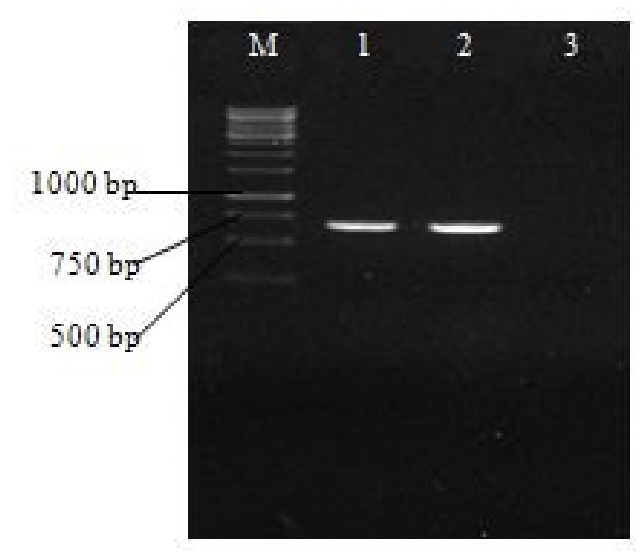

Figure 1. PCR amplification of xylanase gene visualised on $1 \%$ agarose gel. Lane 1 and 2 : xylanase PCR product; Lane 3: negative control. M is a GeneRuler ${ }^{\mathrm{TM}} 1 \mathrm{~kb}$ DNA Ladder (Fermentas). 
Analysis of the cloned xylanase DNA sequence showed it to be in-frame with the Stag, having an ORF of 738 nucleotides with an initiation and a stop codon. Based on the translated amino acid sequence, the calculated molecular weight including the the S-tag and signal peptide was predicted to be $26.86 \mathrm{kDa}$, and the isoelectric point (pI) was predicted at $\mathrm{pH}$ 9.28. With the S-tag removed, the recombinant xylanase is predicted to have 219 amino acids with a molecular weight of 23.9 $\mathrm{kDa}$ and a pI of 9.32. The recombinant xylanase was predicted to have a signal peptide cleavage site between amino acid residues 61 and 62 (sequence not shown) due to presence of the S-tag peptides, while the native xylanase signal peptide cleavage site was predicted to be between residues 28 and 29 (Hussain et al., 2011). The signal peptide was left intact to direct the xylanase into the secretory pathway of $E$. coli. The recombinant mature xylanase was predicted to have a molecular weight of $20.37 \mathrm{kDa}$ and a pI of 9.29. For recombinant gene expression, signal peptide cleavage site can be used as a cleavage position to obtain shorter active proteins for further research and development. This has been shown in isoamylase proteins obtained from pea and potato in which the active isoamylase showed native properties even when expressed as truncated recombinant proteins (Hussain et al., 2003; Hussain \& Martin, 2009).
From Figure 2, both media plates showed a clear zone on the medium around E. coli BL21 (DE3) transformed with recombinant pSTAG plasmid carrying the xylanase insert. The $E$. coli BL21 (DE3) with empty pSTAG plasmid did not show any clear zone on the medium after Congo red staining. Plate $\mathrm{X}$ in which the $E$. coli was not induced with IPTG, showed the presence of a clear zone. Similar observation was made on plate $Y$ induced with IPTG, with presence of clear zone. However, the clear zone on plate $\mathrm{Y}$ is much more pronounced than on plate $\mathrm{X}$. The addition of IPTG had induced bacteria colonies to produce more protein, hence the reason the clearing zone of plate $\mathrm{Y}$ is much more pronounced than of plate $\mathrm{X}$.

As described in Hussain et al. (2011), insilico characterization of the native xylanase from $K$. pneumoniae showed $99.5 \%$ identity to the isolated xylanase from $B$. subtilis (Jalal et al., 2009). Jalal et al. (2011) reported that in heterologous expression, the E. coli secretion system had recognized the signal sequence of the native xylanase and proceeded to cleave it, then secreted out the mature protein into the culture medium. The signal peptide cleavage site for native xylanase of $E$. coli described by Jalal et al. (2011) was reported to be between Ala 28 and Ala 29. This is identical to the signal peptide cleavage site predicted for the native xylanase found in $K$. pneumoniae and heterologously expressed in E.coli BL21
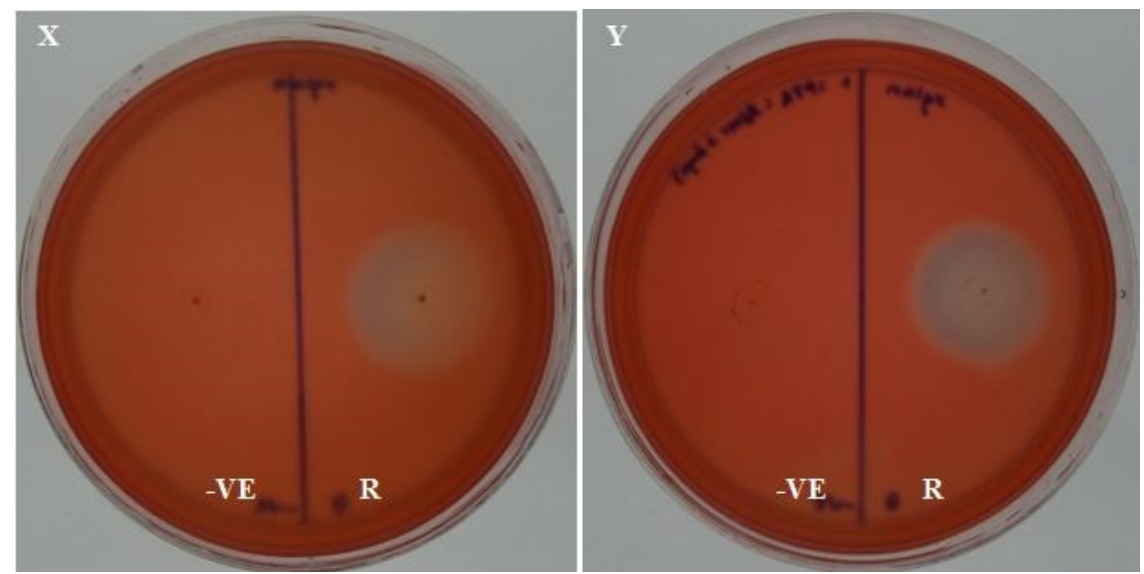

Figure 2. 1\% Congo red staining of agar plates. E. coli BL21 (DE3) with empty pSTAG plasmid (-VE) or recombinant pSTAG plasmid $(\mathrm{R})$ were grown on M9 minimal media plates containing ampicillin and $1 \%$ birchwood xylan. The bacteria colonies were uninduced (X) or induced with IPTG (Y) after overnight incubation. For E. coli BL21 (DE3) with recombinant pSTAG plasmid (R), both uninduced and induced bacteria colonies showed clearing zones. 


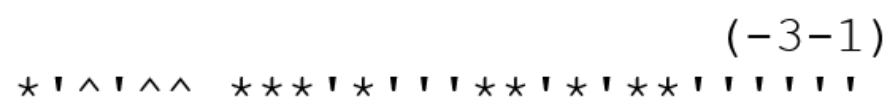

\section{MFKFKKNFLVGLSAALMSISLFSATASA}

Figure 3. Signal peptide of the xylanase. Positively charged lysine residues are marked $\wedge$, highly hydrophobic residues are marked *, and slightly hydrophobic residues are marked '. ( $-3-1)$ indicates the -3 and -1 position relative to cleavage site.

(DE3) described here. The leaky expression followed by secretion of the recombinant mature xylanase into the culture medium would explain the observation of the clearing zone on the medium even without IPTG induction since the secreted recombinant mature xylanase would degrade the xylan in the medium.

Despite the addition of the S-tag to the Nterminal, the signal peptide was still recognized by the E. coli secretory pathway. The signal peptide matches the model for bacterial signal peptides targeting the protein into the SEC pathway and does not match any other pathway as described by Paetzel et al. (2002). The signal peptide contains a positively charged $\mathrm{N}$-domain and hydrophobic H-domain (Figure 3). In the carboxyl-domain, residues in positions -3 and -1 relative to cleavage site Alanine, which is non-polar and small, thus matching the $(-3,-1)$ rule for cleavage by signal peptidase (Nielsen et al., 1997).
E. coli BL21 (DE3) is simple to transform, produce high yield, and have a T7-based expression system, which is one of the most efficient expression system known for $E$. coli. However, the lacUV5 promoter is leaky, and causes relatively high level of basal expression of the recombinant genes even before induction. As such, a more tightly regulated version of the strain, BL21 (DE3) pLysS, is more favoured since it limits the level of uninduced recombinant protein expression (Field et al., 2007; Suvorov, 2008; Zhou et al., 2004).

The expression of the xylanase gene was done at $30^{\circ} \mathrm{C}$ in two ways; with and without the addition of $1 \%$ glucose. The addition of glucose in the media was to prevent leaky expression (Novagen, 1999). The result was checked using SDS-PAGE and Western blot. Analysis of total cell protein extracts showed that the molecular weight of crude recombinant xylanase in lane 1 and lane 3 (Figure 4) matched the expected molecular weight of 25 $\mathrm{kDa}$ predicted from in-silico characterization.

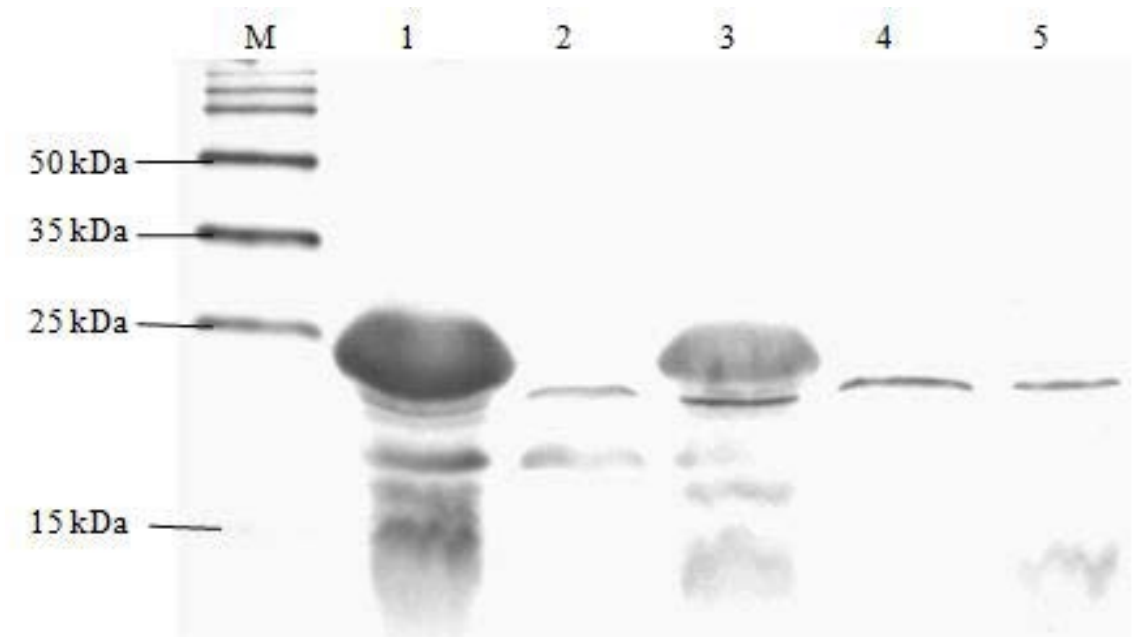

Figure 4. Western blot analysis for xylanase gene expression. Media without glucose (lane 1 and 2) showed higher protein expression compared to media with glucose (lane 3 and 4). Same sample volumes were loaded onto SDS-PAGE. Lane 1: induced recombinant pSTAG plasmid at $30^{\circ} \mathrm{C}$ without glucose; Lane 2 : uninduced recombinant pSTAG plasmid at $30^{\circ} \mathrm{C}$ without glucose; Lane 3: induced recombinant pSTAG plasmid at $30^{\circ} \mathrm{C}$ with $1 \%$ glucose; Lane 4: uninduced recombinant pSTAG plasmid at $30^{\circ} \mathrm{C}$ with $1 \%$ glucose; Lane 5 : induced empty pSTAG plasmid at $30^{\circ} \mathrm{C}$ with $1 \%$ glucose. $\mathrm{M}$ is a Perfect Protein ${ }^{\mathrm{TM}}$ Western Markers (Novagen). 
The expression without the presence of glucose showed the thickest protein band compared to expression in the presence of glucose, although the same volume of extracted proteins were loaded on the SDSPAGE gel. Both uninduced recombinant pSTAG plasmid with xylanase insert and induced empty pSTAG plasmid that acted as a control did not show the presence of a protein band at the predicted molecular weight.

The insoluble, soluble and media fractions were analysed through SDS-PAGE (Figure 5). A $25 \mathrm{kDa}$ protein band, matching the predicted size was detected in the insoluble fraction and media fraction. Western blot analysis of this 25 $\mathrm{kDa}$ band identified it as the full-length recombinant xylanase with S-tag attached. Furthermore, another thick protein band, estimated at $20 \mathrm{kDa}$ was detected in all fractions. The size of this protein band matched the size of the predicted recombinant mature xylanase after signal peptide cleavage, which is $20.37 \mathrm{kDa}$.
This $20 \mathrm{kDa}$ was not detected on the Western blot because the S-tag had been cleaved off by the E. coli secretory system. Instead, the identity of this $20 \mathrm{kDa}$ protein was supported by the MALDI-TOF spectra analysis, where the $20 \mathrm{kDa}$ protein was matched to an endo-1,4-beta-xylanase from Bacillus subtilis (AEP91071) with a score of 392.

This result supports the qualitative assay where xylanase was secreted out and degraded the xylan in the agar. The recombinant mature xylanase was found mainly in the culture medium. It is likely that the $25 \mathrm{kDa}$ xylanase, abundant in the insoluble fraction consists of inclusion bodies which accumulate in the cell because the $E$. coli secretory machinery cannot cope with the large amounts of polypeptide produced by the expression mechanism under the control of the T7 promoter (Novagen, 1999).

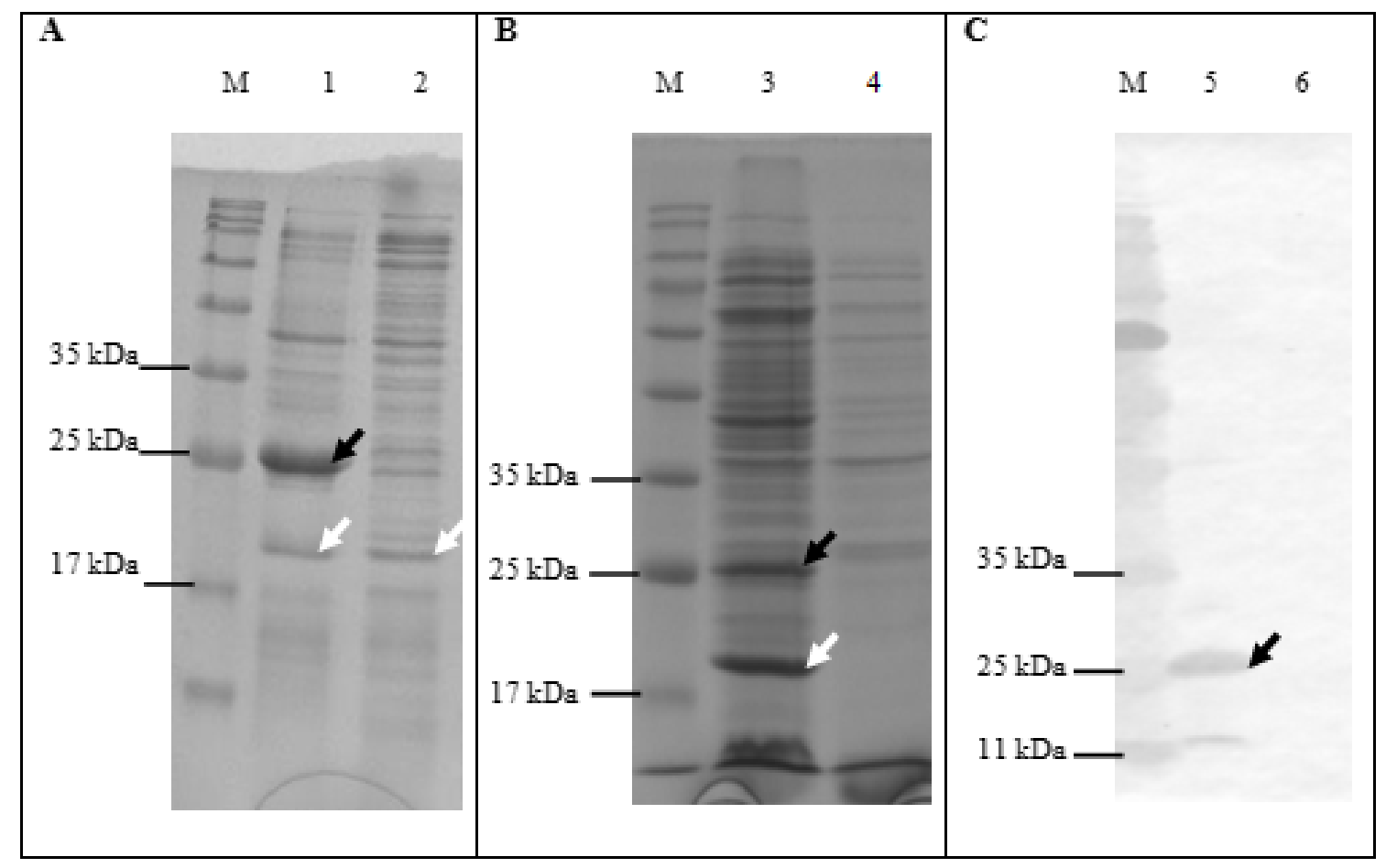

Figure 5. SDS-PAGE and Western blot analysis for proteins extracted from the insoluble, soluble and media fractions. Protein expression was done at $30^{\circ} \mathrm{C}$ with the addition of glucose. The $25 \mathrm{kDa}$ full length recombinant xylanase is indicated by black arrows while the secreted $20 \mathrm{kDa}$ recombinant mature xylanase is indicated by the white arrows. $\mathrm{M}$ is a BlueRAY Prestained Protein Ladder (GeneDireX). A. 15\% SDS-PAGE gel for insoluble and soluble fractions. Lane 1: insoluble fraction; Lane 2: soluble fraction. B. 15\% SDS-PAGE gel for media fraction. Lane 3: induced recombinant pSTAG with xylanase insert; Lane 4: induced empty pSTAG plasmid. C. Western blot for media fraction separated on 10\% SDS-PAGE gel. Lane 5: induced recombinant pSTAG with xylanase insert; Lane 6: induced empty pSTAG plasmid. 
A xylanase gene from Bacillus that was expressed in E. coli had been reported to be distributed in extracellular, intracellular and periplasmic fractions (Huang et al., 2006). However, recombinant xylanases were commonly found to be in the insoluble fraction of the cytoplasm, hinting that even after optimization, the expression of the xylanase gene produces protein that is insoluble and accumulates in inclusion bodies (Yin et al., 2008). In many cases the expressed protein is insoluble and accumulates in inclusion bodies, especially under conditions of high level expression. Several strategies are available to improve the solubility of the expressed protein such as change of the media composition, production of the protein at low temperature $\left(20^{\circ} \mathrm{C}\right.$ or lower), genetic modifications of $E$. coli strains, and co-production of folding modulators and fusion tags (Altenbuchner \& Mattes, 2006; Garcìa-Fruitòs et al., 2009). However, sometimes despite of all efforts the target protein will still be expressed in the inclusion bodies. In this case, the other option available is to carry out protein denaturation followed by refolding of the denatured protein in vitro.

The secretion of xylanase into the medium does not only simplify purification of the xylanase, it also decreases proteolysis, reduces levels of contaminants, and cell disruption can be avoided (Jonasson et al., 2002). This 29 amino-acid transport peptide could be used as a gene fusion partner, for secretion of other heterologous proteins in E. coli since it is recognized by both gram positive and gram negative bacteria.

The activity of the crude recombinant xylanase was $2.015 \mathrm{U} / \mathrm{mL}$, which is more than 3 times higher compared to the activity of the crude native xylanase of $K$. pneumoniae isolated by Hussain et al. (2011), which was $0.642 \mathrm{U} / \mathrm{mL}$ at the maximum. Based on the latter activity value, it was expected that higher activity could be obtained once the gene was isolated and heterologously expressed as crude recombinant xylanase. This expectation was based on research by Jalal et al. (2009), Helianti et al. (2008), and Lee et al. (2008) where purified recombinant xylanase showed an increase in its activity compared to the activity of native xylanase.

\section{CONCLUSION}

K. pneumoniae xylanase was successfully expressed in the heterologous expression system of E. coli BL21 (DE3). The characterised enzyme showed an increase in activity compared to native xylanase. The E. coli BL21 (DE3) however showed leaky expression secretion system prior to being induced by IPTG. Analysis of the recombinant xylanase in the soluble and insoluble fractions showed that the recombinant xylanase protein is secreted out of the cell as a soluble $20 \mathrm{kDa}$ mature protein. Meanwhile, in the insoluble fraction, the $20 \mathrm{kDa}$ recombinant mature xylanase as well as the $25 \mathrm{kDa}$ recombinant xylanase containing uncleaved transit peptide accumulated in the cell as inclusion bodies because the E. coli secretion system cannot cope with such high production of recombinant protein.

\section{ACKNOWLEDGEMENTS}

The authors would like to thank Ministry of Higher Education Malaysia and Universiti Malaysia Sarawak for the facilities and financial support to conduct this research through FRGS grant 961/2013(02). Special thanks to Dr Md Nuruzzaman of School of Food Science and Technology, Universiti Malaysia Terengganu for comments and suggestions during preparation of the manuscript.

\section{REFERENCES}

Altenbuchner, J. \& Mattes, R. (2006). Escherichia coli. In G. Gellissen (Ed.), Production of recombinant proteins: novel microbial and eukaryotic expression systems. Germany: John Wiley \& Sons. Pp. 7-35.

Edwards, A., Borthakur, A., Bornemann, S., Venail, J., Denyer, K., Waite, D., Fulton, D., Smith, A. \& Martin, C. (1999). Specificity of starch synthase isoforms from potato. European Journal of Biochemistry, 266: 724-736.

Field, S., Udalova, I. \& Ragoussis, J. (2007). Accuracy and reproducibility of proteinDNA microarray technology. In H. Seitz (Ed.), Analytics of protein-DNA interactions. New York: Springer. Pp 87109. 
Garcìa-Fruitòs, E., Gonzàlez-Montalbàn, N., Martìnez-Alonso, M., Rinas, U. \& Villaverde, A. (2009). Systems-level analysis of protein quality in inclusion body-forming Escherichia coli cells. In S.Y. Lee (Ed.), Systems biology and biotechnology of Escherichia coli. Netherlands: Springer. Pp 295-326.

Gardener, B.B.M. (2004). Ecology of Bacillus and Paenibacillus spp. in agricultural systems. Phytopathology, 94(11): 12521258.

Helianti, I., Nurhayati, N. \& Wahyuntari, B. (2008). Cloning, sequencing, and expression of a $\beta-1,4$-endoxylanase gene from Indonesian Bacillus licheniformis strain I5 in Escherichia coli. World Journal of Microbiology and Biotechnology, 24(8): 1273-1279.

Huang, J., Wang, G. \& Xiao, L. (2006). Cloning, sequencing and expression of the xylanase gene from a Bacillus subtilis strain B10 in Escherichia coli. Bioresource Technology, 97(6): 802-808.

Hussain, H., Mant, A., Seale, R., Zeeman, S., Hinchliffe, E., Edwards, A., Hylton, C., Bornemann, S., Smith, A.M., Martin, C. \& Bustos, R. (2003). Three isoforms of isoamylase contribute different catalytic properties for the debranching of potato glucans. The Plant Cell, 15(1): 133-149.

Hussain, H. \& Martin, C. (2009). Comparative analysis of primary and secondary structure for pea isoamylase isoforms predicts different catalytic properties against glucan substrates. Starch/-Stärke, 61(10): 570-577.

Hussain, M.H., Chong, N.F.M., Chan, C.S.W., Safarina, A. \& Husaini, A. (2011). Xylanase gene from a locally isolated bacterium. Malaysian Applied Biology, 40(1): 33-38.

Jalal, A., Rashid, N., Ahmed, N., Iftikhar, S. \& Akhtar, M. (2011). Escherichia coli signal peptidase recognizes and cleaves the signal sequence of xylanase from a newly isolated Bacillus subtilis strain R5. Biochemistry (Moscow), 76(3): 347-349.
Jalal, A., Rashid, N., Rasool, N. \& Akhtar, M. (2009). Gene cloning and characterization of a xylanase from a newly isolated Bacillus subtilis strain R5. Journal of Bioscience and Bioengineering, 107(4): 360-365.

Jonasson, P., Liljeqvist, S., Nygren, P.A. \& Stahl, S. (2002). Genetic design for facilitated production and recovery of recombinant proteins in Escherichia coli. Biotechnology and Applied Biochemistry, 35: 91-105.

Kulkarni, N., Shendye, A. \& Rao, M. (1999). Molecular and biotechnological aspects of xylanases. FEMS Microbiology Reviews, 23(4): 411-456.

Lee, C.C., Kibblewhite-Accinelli, R.E., Smith, M.R., Wagschal, K., Orts, W. J. \& Wong, D.W. (2008). Cloning of Bacillus licheniformis xylanase gene and characterization of recombinant enzyme. Current Microbiology, 57(4): 301-305.

Nakamura, S., Wakabayashi, K., Nakai, R., Aono, R. \& Horikoshi, K. (1993). Purification and some properties of an alkaline xylanase from alkaliphilic Bacillus sp. strain 41M-1. Applied and Environmental Microbiology, 59(7): 23112316.

Nielsen, H., Engelbrecht, J., Brunak, S. \& Heijne, G.V. (1997). Identification of prokaryotic and eukaryotic signal peptides and prediction of their cleavage sites. Protein Engineering, 10(1): 1-6.

Novagen (1999). pET System Manual ( $8^{\text {th }}$ edition). Accessed online from https://labs.fhcrc.org/hahn/Methods/bioche m_meth/pet.pdf.

Paetzel, M., Karla, A., Strynadka, N.C.J. \& Dalbey, R.E. (2002). Signal peptidases. Chemical Reviews, 102: 4549-4579.

Singh, R.P., Dwivedi, P., Vivekanand \& Kapur, N. (2007). Xylanases: structure, molecular cloning and regulation of expression. In R.C. Kuhad \& A. Singh, (Eds.), Lignocellulose biotechnology: Future prospects. New Delhi: I.K. International Publishing House. Pp 149159. 
Suvorov, M. (2008). Regulation of cell wall biosynthesis and resistance to antibiotics (Doctoral dissertation). Indiana: University of Notre Dame. ProQuest Database (3318074).

Te'o, V.S.J., Cziferszky, A.E., Bergquist, P.L. \& Nevalainen, K.M.H. (2000). Codon optimization of xylanase gene $x y n B$ from the thermophilic bacterium Dictyoglomus thermophilum for expression in the filamentous fungus Trichoderma reesei. FEMS Microbiology Letters, 190(1): 1319.

Touzel, J.P., O'Donohue, M., Debeire, P., Samain, E. \& Breton, C. (2000). Thermobacillus xylanilyticus gen. nov., sp. nov., a new aerobic thermophilic xylandegrading bacterium isolated from farm soil. International Journal of Systematic and Evolutionary Microbiology, 50(1): 315-320.
Wanarska, M., Hilderbrandt, P. \& Kur, J. (2007). A freeze-thaw method for disintegration of Escherichia coli cells producing $\mathrm{T} 7$ lysozyme used in $\mathrm{pBAD}$ expression systems. Acta Biochimica Polonica, 54(3): 671-672.

Yin, E., Le, Y., Pei, J., Shao, W. \& Yang, Q. (2008). High-level expression of the xylanase from Thermomyces lanuginosus in Escherichia coli. World Journal of Microbiology and Biotechnology, 24(2): 275-280.

Zhou, L., Zhang, K. \& Wanner, B.L. (2004). Chromosomal expression of foreign and native genes from regulatable promoters in Escherichia coli. In P. Balbás \& A. Lorence (Eds.), Recombinant gene expression: reviews and protocols. USA: Humana Press. Pp 132. 